\author{
Military Technical College \\ Kobry El-Kobbah, \\ Cairo, Egypt
}

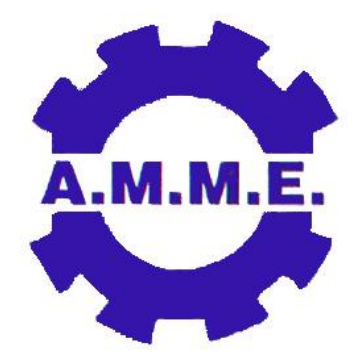

$14^{\text {th }}$ International Conference on Applied Mechanics and Mechanical Engineering.

\title{
Adaptive Tyre Pressure Control for Off-Road Vehicles
}

By
H. M. El-Zomor ${ }^{1}$
S. M. Shaaban ${ }^{2}$
S. M. El-Demerdash ${ }^{2}$
M. A. Emam²

\begin{abstract}
:
Off-road vehicles' performance depends strongly on two major factors; the vehicle design, and the soil type. One of the efficient methods used to ameliorate vehicle performance is adjusting the inflation pressure to suit the ground bearing capacity. These present work deals with designing and building a laboratory test rig that enables adjusting the inflation pressure of a single tyre according to a specific control strategy based on getting a specific tyre deformation that suit the drive condition on soft soils such as fine sand.

The built instrumentation system receives, processes, and sends signal data from and to the tested tyre by using the LabView software. A large volume of experimental data related to tyre load, pressure, soil density, and resulting tyre deformation and soil sinkage have been used to develop a relationship between tyre sinkage and load for three soil densities (loose medium - dense). The relationship represents the base for the control strategy. The results of application of the used control strategy showed that tyre pressure can be adaptively controlled to reach the so called tyre flotation pressure within an acceptable time response.
\end{abstract}

\section{Keywords:}

Off-Road mobility, Tyre pressure control, Tyre floatation, Soil trafficability.

\footnotetext{
${ }^{1}$ Higher Technological Institute $10^{\text {th }}$ of Ramadan City $-6^{\text {th }}$ of October Branch - EGYPT, email: haythamelzomor@hotmail.com.

${ }^{2}$ Faculty of Engineering in Mattaria - Helwan University - EGYPT.
} 


\section{Introduction:}

Wheel-terrain interaction has been shown to play a critical role in rough-terrain vehicle mobility [1]. The tyre is an important form of running gear for off-road vehicles. Research studies indicate that about $20-55 \%$ of the energy developed to the drive wheels is wasted in the tyre-soil interaction. This energy is not only wasted but it is also resulting compaction of soil and damages of tyre.

Since the earliest days of off-road vehicles, the ground pressure underneath vehicles has been taken as an indicator of mobility. The vehicle having a low ground pressure will be able to access more hard types of terrain than the vehicle with higher ground pressure. In the military situation it is need to specify the off- road vehicle capability to ensure that it will be able to fulfill its role. Similarly, in determining which vehicles can be usefully in a particular campaign. [2]

As a result of the previous studies, the knowledge of the effects of tyre characteristics and soil conditions on vehicle mobility at the tyre-soil interface is still limited, so it is required to make more experimental work to predict the vehicle performance on the off-road terrain.

\section{Background:}

\subsection{Tyre-Soil Interaction}

The ability of vehicles to traverse soft soils is an important aspect of their performance. There is always much debate as to whether the vehicles for particular roles should be wheeled or tracked. Therefore it is important to compare the tractive performance of wheeled and tracked vehicles, particularly in the low traction and go/no-go region.

Bekker [3] generalized earlier equations into a single form applicable to homogeneous soil of any type. Dwyer [4] claimed that Bekker's method of predicting tractive performance provided a good insight into the effect of different parameters on the design of any off road vehicle. However, it suffers from the difficulty of making accurate measurements of the required soil parameters. For this reason the cone penetrometer and mobility number approaches have been developed for predicting the field performance of tyres.

The researchers developed many models to predict the traction of vehicles. Yong in 1972 [5] reported the analytical requirements for predicting vehicle mobility, traction in particular. Yong developed models for tyres that accounted for energy losses from wheel slippage, as well as soil failure. Brixius in 1987 [6] developed a traction prediction equations for bias ply tyres. Zoz in 1987 [7] incorporated the models into a spreadsheet with an algorithm that accounted for weight transfer from the hitch loads. Wood, et al. 1990 [8] determined the relationship between thrust and dynamic load for radial tyres to be linear using radial tyres in the soil bins at the National Soil Dynamics Laboratory (NSDL) in Auburn, Alabama.

\subsection{Effect of Reducing Tyre Inflation Pressure}

Since the benefits of central tyre inflation system (CTIS) demonstrated in World War II, CTIS has become standard equipment on most wheeled military vehicles [9]. The use of CTIS 
leads to improved traction, ride, and mobility for tactical vehicles, particularly in off-highway conditions. Adams in 2002 showed that reducing inflation pressure in tyres improves the ride. Comparing his results to the ISO2631 standard (standard for evaluating whole body vibration levels), concluded that CTIS would seem to be a reasonable choice of technologies to improve the ride of the vehicle without a substantial redesign or increase in cost [10].

Inflation pressure has long been recognized as an important variable in the optimization of tyre performance. Research has shown positive benefits of reducing inflation pressure on offroad Terrain [11]. Raper et al in 1995 showed by experimental work that by decreasing inflation pressure, soil-tyre interface pressures near the center of the tyre is also are decreased, and the length of tyre contacting the soil is increased [12]. Pytka et al showed that reducing inflation pressure has a positive effect on traction and wheel-soil interactions on two different soil surfaces (sand - Loess) investigated [13]. McDonald studied the effects of inflation pressure and dynamic load on soil compaction for a forwarder tyre. Also, he concluded that the reduction in inflation pressure at a given dynamic load tends to decrease bulk density, soil cone index, and rut depth [14].

One of the disadvantages is presented by William et al. [15] that tyre life is shortened by under inflation as well as over inflation. Under inflation causes abnormal flexing which results in a series of breaks and separation of the cord fabric and sidewall cracks. But it can be safely solved in the early 1990s, by the Tire and Rim Association adopted a new load inflation table, with minimum inflation pressures reduced to $40 \mathrm{kPa}$.

It is fair to say that, from the previous review it is found that more effort is needed to found the suitable tyre inflation pressure according to the terrain situation and maintain this pressure according to the type of terrain without taking to account the driver experience.

\section{Test Rig:}

A test rig has been designed and built at the Higher Technological Institute- Tenth of Ramadan City, Sixth of October branch. It has been constructed using numerous fabricated components. The main components of the test rig are:

- Metallic frame.

- Pneumatic circuit, and

- Control system.

The test rig frame has been designed to enable testing various tyre sizes from ( $\phi=450$ to $650 \mathrm{~mm}$ ). The test rig shown in Figure 1consists of four main parts (table, tower, arm, wheel mounting). The main structure is composed of $C$ shaped channel steel, size $10 \mathrm{~cm} \times 5 \mathrm{~cm} \times 2$ $\mathrm{mm}$. Maximum loading at the free end is $350 \mathrm{~kg}$, transmitted to the tested tyre with leverage ratio 3.0 to apply $10.6 \mathrm{kN}$, as shown in Figure 2. 


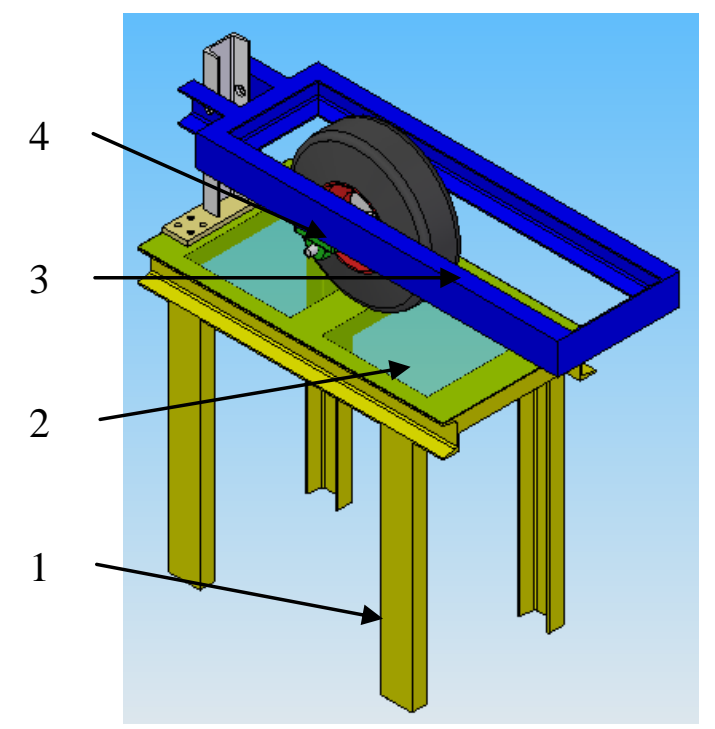

1 - Table

2 - Tower

$3-$ Arm

4 - Wheel Mounting

Figure (1): The test rig frame.

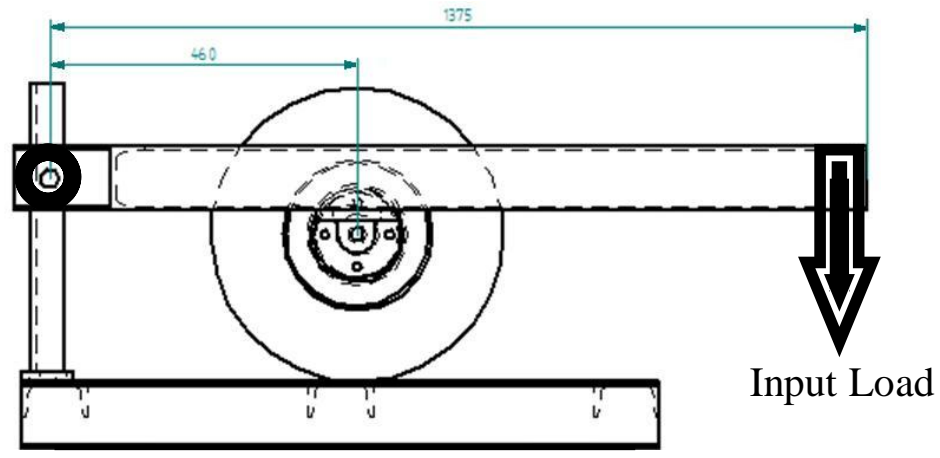

Figure (2): Load application on the tested tyre.

Calculation of the stresses and the factor of safety have been performed for the test rig main parts by the Cosmos Express attached in Solid Works Software, as in Figure 3.
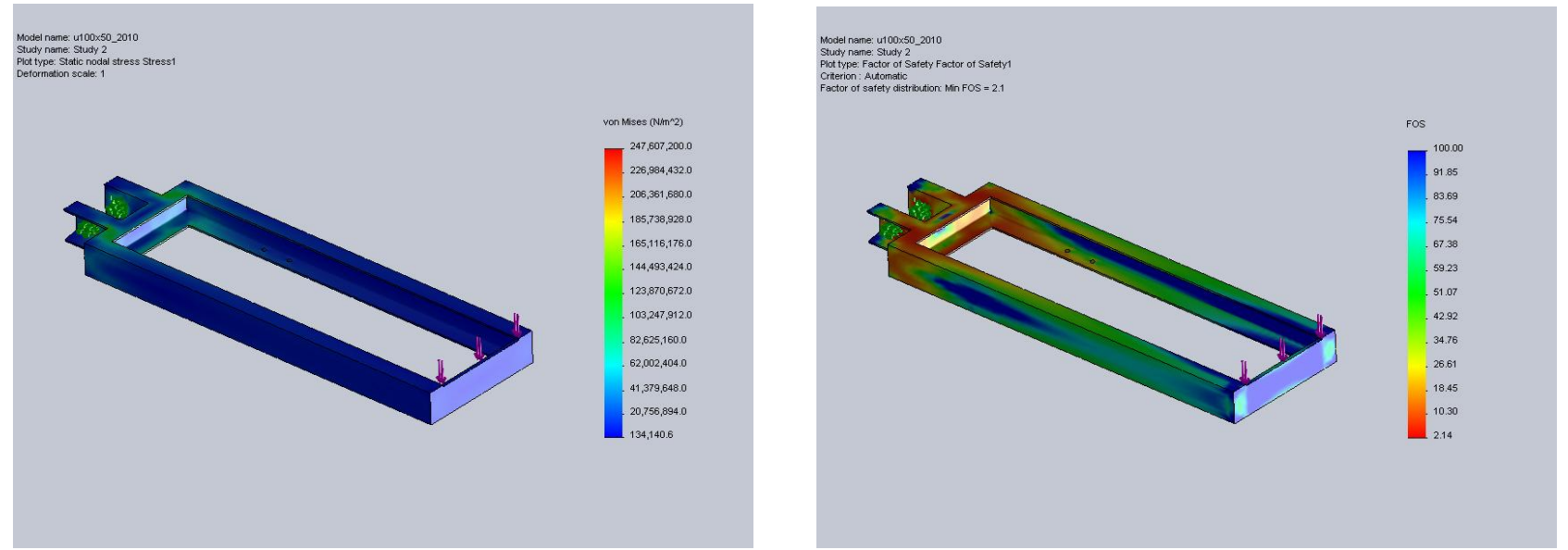

Figure (3): The frame in the design process; left side: stress analysis and right side: factor of safety. 
A pneumatic circuit has been designed and assembled to enable inflating and deflating the tyre. Main parts of the circuit are; a compressor delivering max air pressure of 10 bar and its attachments, a 5/3 directional valve double solenoid controlled, a variable pressure regulator, pressure gauges, a variable non-return throttle valve, and silencers, as shown by Figure 4.
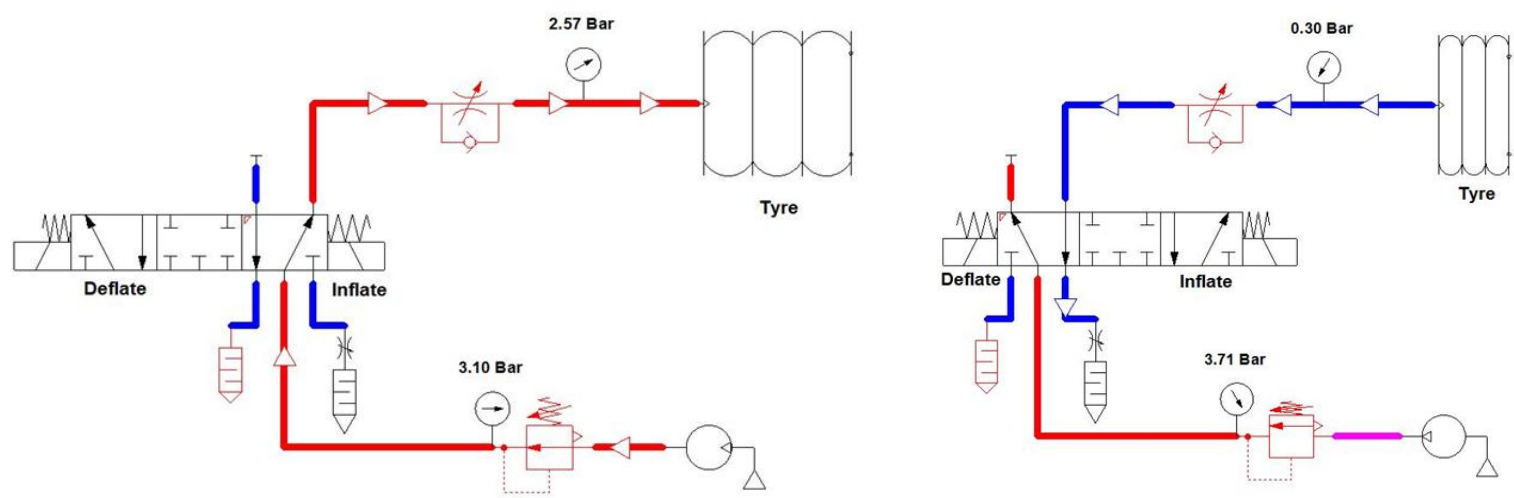

Figure (4): The pneumatic circuit diagram in the simulation process, the left side: during tyre inflation, and right side: image of tyre deflation.

Instrumentations and sensors used for circuit monitoring have been carefully selected to meet the requirements for this test rig. A displacement transducer with stroke ranges of \pm 2 in. located on the arm side in the center of the tested tyre to measure the vertical deflection. The transducer body is held by two fixation points. A pressure transducer, all-welded stainless steel sensor built for high accuracy and measurement stability. Maximum pressure of $3000 \mathrm{psi}$, used to measure the tested tyre inflation pressure. Data acquisition card and Labtop computer is in-housed a LabView software to receive, monitor, display and store the measured signals from the respective transducers in ASCII code format and transmit the signal to the actuator (5/3 directional valve). The diagram of the data acquisition system with associate transducers is shown in Figure 5.

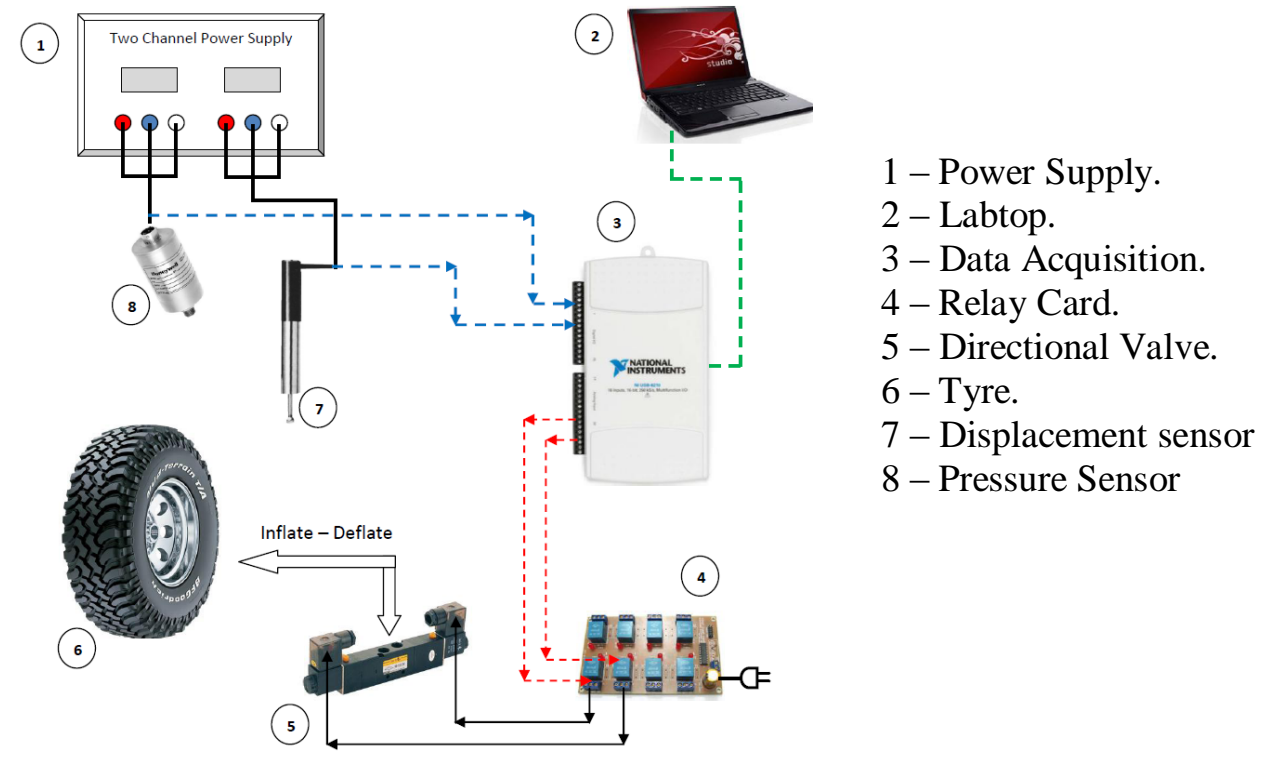

Figure (5): The Control system for inflating and deflating the tested tyre. 


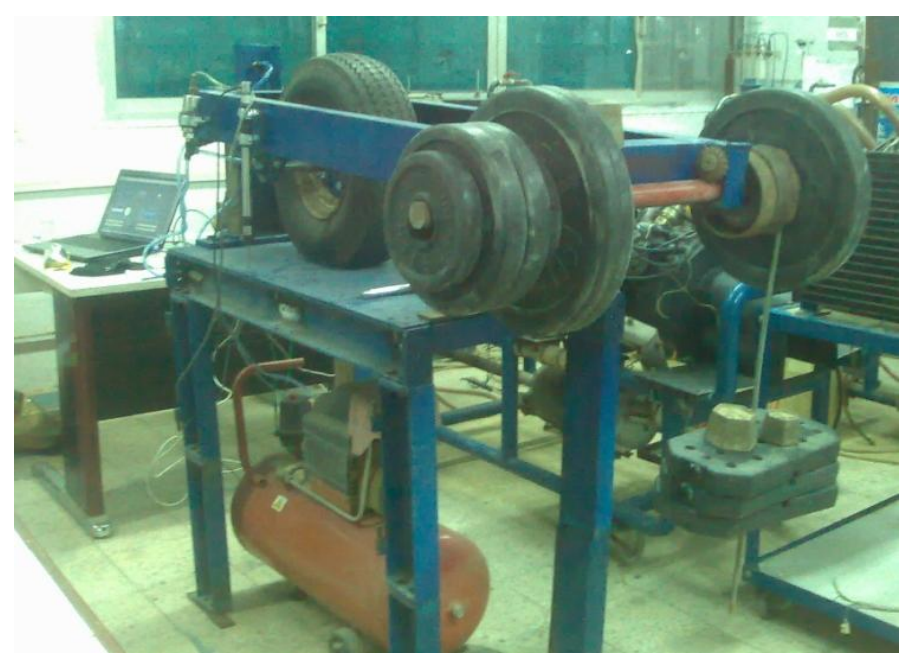

\section{Methodology:}

Figure (6): Photo for the developed test rig.

The floatation (optimum) pressure is determined by a program running under LabView software designed especially for this work (user screen seen in figure 10). The program calculates the pressure and the corresponding sinkage of the tyre at this situation by using 3D meshing maps for load-deflection-pressure and sinkage-load-pressure were implemented and at three different types of sand densities (loose, medium, and dense), an example for loose soil is shown in Figure 7 and Figure 8.

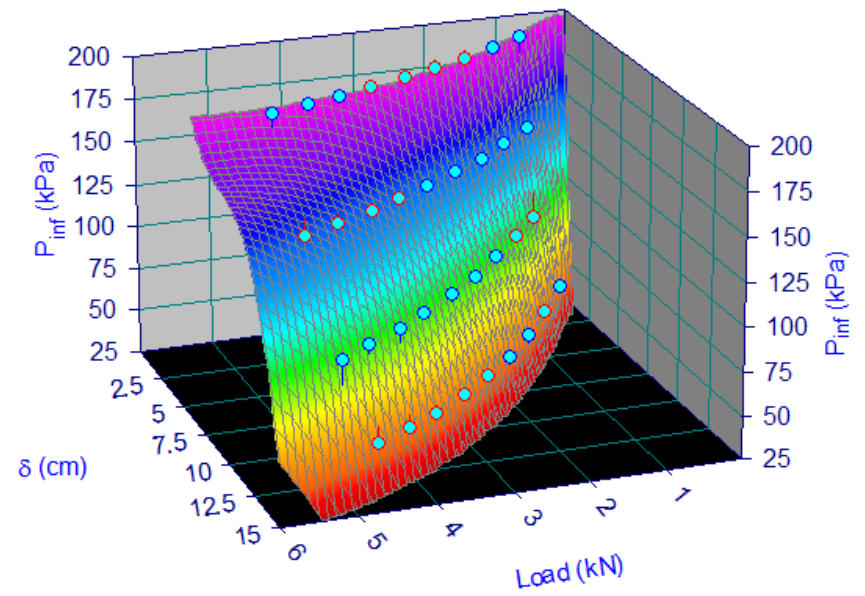

Figure (7): Load-deflection-pressure map. 


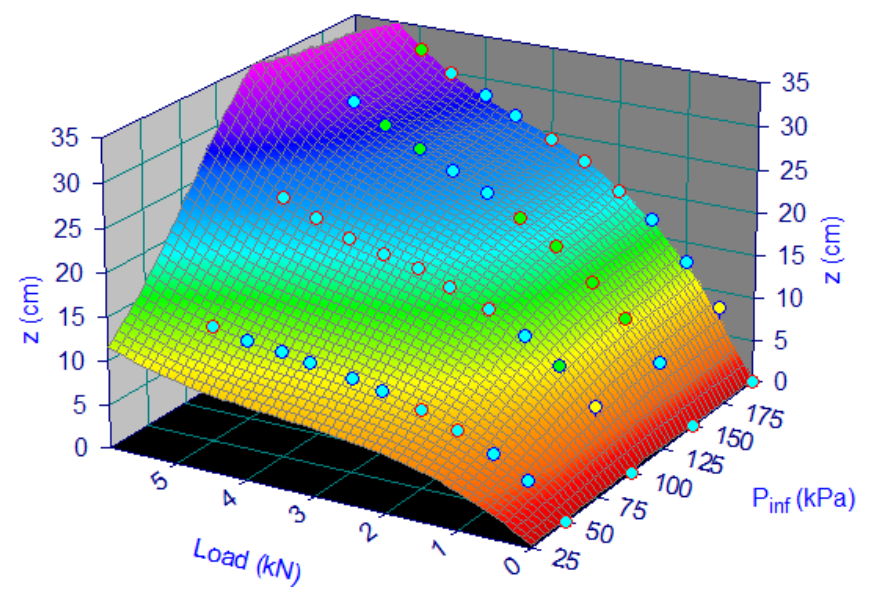

Figure (8): The 3D meshing map implemented especially for this work, data taken from reference [16]

To adjust tyre inflation to the floatation pressure, the calculated sinkage has been compared with the measured real time tyre deflection. Then tyre pressure has been adjusted so that soil sinkage and tyre deflection are equalized, shown in Figure 9.

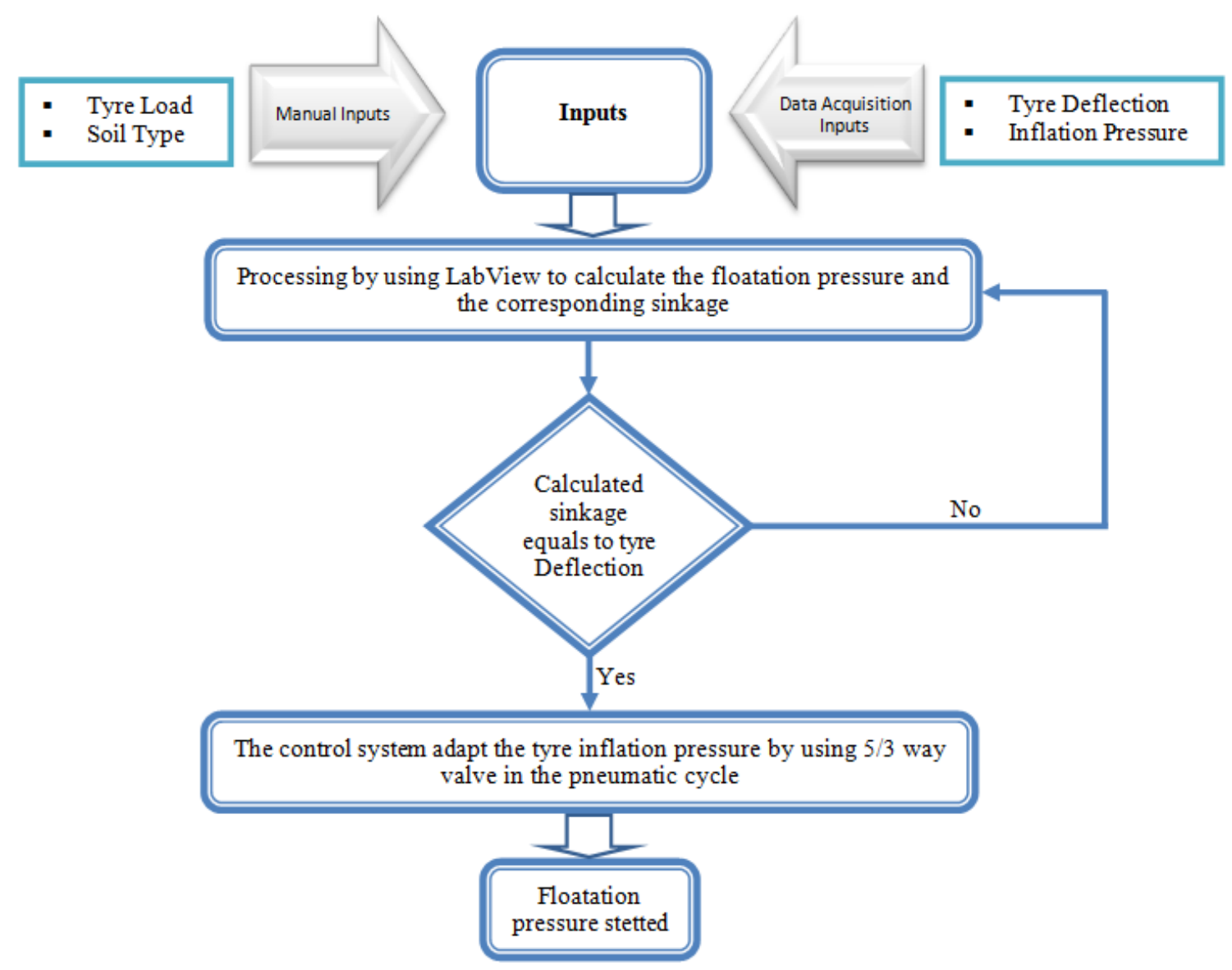

Figure (9): A flowchart for the adaptive floatation tyre pressure program 


\section{Results and Discussions:}

The designed and built test rig has proven its capability that allows conducting several measurements that aimed at finding out the optimum tyre pressure that makes the tyre floating on the soil.

Tests that can be carried out using the test rig are mainly;

- Load vs deflection at various inflation pressures.

- Tyre footprint vs deflection at different inflation pressures.

- Tyre hysteresis vs inflation pressure.

- Tyre stiffness vs inflation pressure.

Results of the conducted tests show a good time response of setting the required floatation pressure either on inflating or deflating the tyre; and the control low of the floatation pressure shown in eq. (1). The time response ranges between (10 sec and 60sec), this depends upon tyre initial pressure, an example is shown in Figure 10.

$$
P_{\text {flot }}=P_{\text {flot }} f\left(L, z, \square, \rho_{\text {soil }}\right)
$$

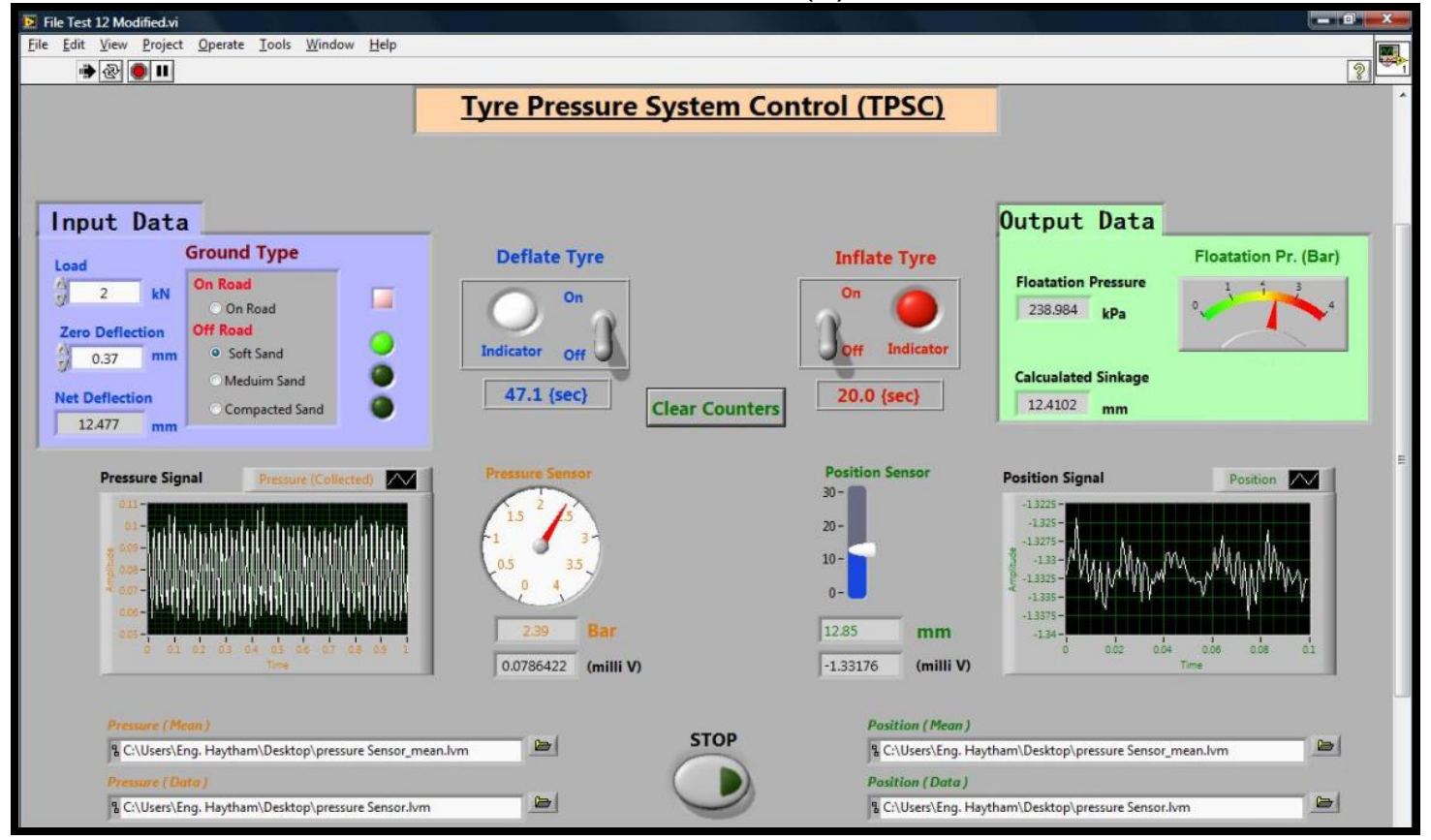

Figure (10): User Screen for the LabView program, shows the floatation pressure 238 $k P a$ for $2 \mathrm{kN}$ load applied on tyre moving on soft soil.

\section{Conclusions:}

A control strategy for adjusting vehicles tyres' inflation to suit ground traffic ability has been developed. The conducted experimental investigation using the designed and built test rig showed that vehicles tyre flotation pressure can be adjusted successively and its response time is good. Using the developed control strategy enables automatic adjusting the tyre inflation pressure without driver interference. 


\section{References:}

[1] G. Bekker, Introduction to Terrain-Vehicle Systems, University of Michigan Press, 1969.

[2] J.G. Hetherington, The Applicability of the MMP Concept in Specifying Off-Road Mobility for Wheeled and Tracked Vehicles, Journal of Terramechanics, Vol. 38, P. 6370, 2001.

[3] M.G. Bekker, Off-the-Road Locomotion, Ann Arbor, Ml: The University of Michigan Press, 1960.

[4] M.J. Dwyer, The Tractive Performance of Wheeled Vehicles, Journal of Terramechanics, Vol.21, No. I, P.19-34, 1984.

[5] R.N. Yong, Analytical Predictive Requirements for Physical Performance of Mobility, ASAE Paper No. 72, P.616, 1972.

[6] W.W. Brixius, Traction Prediction Equations for Bias Ply Tires, ASAE Paper No. 87, P.1622, 1987.

[7] F.M. Zoz, Predicting Tractor Field Performance, ASAE Paper No. 87, P.1623, 1987.

[8] R.K. Wood, E.C. Burt, and C.E. Johnson, Tire Thrust As Affected By Dynamic Load, Proceedings of the $10^{\text {th }}$ International Conference of the ISTVS in Japan, P. 205-216, Elsevier Science, 1990.

[9] R.W. Kaczmarek, Central Tire Inflation Systems (CTIS) - A Means to Enhance Vehicle Mobility, Proceedings of the $8^{\text {th }}$ International Conference of the ISTVS. England, 1984.

[10] B.T. Adams, Central Tire Inflation for Agricultural Vehicles, PhD Thesis, University of Illinois at Urbana, Champaign, 2002.

[11] E.C. Burt and A.C. Bailey, Load and Inflation Pressure Effects on Tires. Transaction of ASAE, Vol. 25, No. 4, P. 881-884, 1982.

[12] R.L. Raper, A.C. Bailey, E.C. Burt, The Effects of Reduced Inflation Pressure on SoilTire Interface Stresses and Soil Strength, Journal of Terramechanics, Vol. 32, No. 1, P. 43-51, 1995.

[13] J. Pytka, J. Dabrowski, M. Zajac, P. Tarkowski, Effects of Reduced Inflation Pressure and Vehicle Loading on Off-Road Traction and Soil Stress and Deformation State, Journal of Terramechanics, Vol. 43, P. 469-485, 2006.

[14] T. McDonald, T. Way, B. Löfgren, B. Seixas, M. Landström, Load and Inflation Pressure Effects on Soil Compaction of Forwarder Tires, Proceedings of the Joint IUFRO Conference, P. E67-E70, Canada, 1996.

[15] J.P. William, W.P. Donald, E.B. Frank, Modern Farm Power, Reston, VA; 1979.

[16] M. Abde Al-Hafiz, Effect of Tyre-to-Sandy Soil Relative Stiffness on Tyre Deformation and Sinkage, M.Sc. Thesis, Helwan University, 2006.

\section{Nomenclatures:}

$\begin{array}{llll}\mathrm{z} & \ldots & \text { Tyre sinkage } & (\mathrm{cm}) \\ \square & \ldots & \text { Tyre deflection } & (\mathrm{cm}) \\ \mathrm{L} & \ldots & \text { Load } & (\mathrm{kN}) \\ \mathrm{P}_{\text {inf }} & \ldots & \text { Inflation Pressure } & (\mathrm{kPa}) \\ \mathrm{P}_{\text {flot }} & \ldots & \text { Floatation Pressure } & (\mathrm{kPa}) \\ \rho_{\text {soil }} & \ldots & \text { Soil Density } & \left(\mathrm{kg} / \mathrm{m}^{3}\right) \\ \phi & \ldots & \text { Tyre Diameter } & (\mathrm{mm})\end{array}$

